\title{
Men are the main COVID-19 transmitters: behavior or biology?
}

\author{
Monize V. R. Silva ${ }^{1}$ Mateus V. de Castro ${ }^{1}$ Maria Rita Passos-Bueno ${ }^{1} \cdot$ Paulo A. Otto ${ }^{2}$ Michel S. Naslavsky ${ }^{2}$ \\ Mayana Zatz ${ }^{1}$
}

Received: 25 October 2021 / Accepted: 12 January 2022

Published online: 24 January 2022

(c) The Author(s) 2022 OPEN

\begin{abstract}
Background COVID-19 has affected millions of people worldwide. Clinical manifestations range from severe cases with lethal outcome to mild or asymptomatic cases. Although the proportion of infected individuals does not differ between sexes, men are more susceptible to severe COVID-19, with a higher risk of death than women. Also, men are pointed out as more lax regarding protective measures, mask wearing and vaccination. Thus, we questioned whether sex-bias may be explained by biological pathways and/or behavioral aspects or both.

Methods Between July 2020 and July 2021, we performed an epidemiological survey including 1744 unvaccinated adult Brazilian couples, with there was at least one infected symptomatic member, who were living together during the COVID19 infection without protective measures. Presence or absence of infection was confirmed by RT-PCR and/or serology results. Couples were divided into two groups: (1) both partners were infected (concordant couples) and (2) one partner was infected and the spouse remained asymptomatic despite the close contact with the COVID-19 symptomatic partner (discordant couples). Statistical analysis of the collected data was performed aiming to verify a differential transmission potential between genders in couples keeping contact without protective measures.

Results The combination of our collected data showed that the man is the first (or the only) affected member in most cases when compared to women and that this difference may be explained by biological and behavioral factors.

Conclusions The present study confirmed the existence of gender differences not only for susceptibility to infection and resistance to COVID-19 but also in its transmission rate.
\end{abstract}

\section{Highlights}

- There are sex differences in COVID-19 susceptibility and transmission between couples highly exposed to SARS-Cov-2 without protective measures;

- Men are more efficient virus transmitters than women;

- Sex-bias in COVID-19 transmission can be explained by differences in viral load in saliva, immune response and also behavioral protective differences between genders.

Keywords COVID-19 · Household transmission · Behavior · Adult couples · SARS-CoV-2

Monize V. R. Silva and Mateus V. de Castro contributed equally for the manuscript

Mayana Zatz, mayazatz@usp.br| ${ }^{1}$ Human Genome and Stem Cell Research Center (HUG-CELL), Biosciences Institute, University of Sao Paulo, Sao Paulo, SP, Brazil. ${ }^{2}$ Department of Genetics and Evolutionary Biology, Biosciences Institute, University of Sao Paulo, Sao Paulo, SP, Brazil. 


\section{Introduction}

Since the first reported case of COVID-19 in December 2019, some 200 million individuals have been infected by the novel coronavirus. Global epidemiological data revealed that age increases the risk of dying from COVID-19 because of the significant number of older adults with comorbidities [1-4]. Moreover, although there are no gender differences in the proportion of people infected by SARS-CoV-2, men are more susceptible to develop severe COVID-19 [5, 6].

COVID-19 pandemic caused a significant number of deaths worldwide, but the prevalence of comorbidities $[7,8]$, lower education levels, socioeconomic inequalities as the healthcare system inexperience to deal with the pandemic [9, 10] contributed to the increase of COVID-19 cases and deaths in low- and middle-income countries (LMICs) [11-13]. Most of these countries still show inadequate vaccination programs, lack of an accurate and rapid diagnosis as well as poor viral surveillance [10,14-16], contributing for the emergence of COVID-19 waves and new SARS-CoV-2 variants [17, 18].

Independently of age, men are more likely to have complications by COVID-19 than women and if hospitalization is required, males are more at risk of death than females [19]. Interestingly, comparable gender differences also occur for other viral infections [20]. Furthermore, some behavioral aspects such as COVID-19 prevention and control measures vary between genders. A survey conducted in March-April 2020 indicated that men are more reluctant than women to wear protective masks and respect social distancing [21].

A recent survey conducted with almost 2000 American adults showed that the importance of masks for protection differ considerably between genders and males are more likely to consider masks as an infringement on their independence and freedom [22]. Another survey with 2500 Americans showed that males are less inclined to wearing masks than females, although both genders consider masks shameful [23]. Other protective practices as handwashing and sanitizer use had been previously reported as more common among females [24] and this tendency is the same for COVID-19 pandemic [25].

Interestingly, preliminary surveys to evaluate sex-differences for COVID-19 vaccination intention showed that females intended less to be vaccinated, probably due to the fear as to side effects or even the desire to "not the first to be vaccinated" [26-29]. Nonetheless, updated data compiled by The COVID-19 Sex-Disaggregated Data Tracker initiative by Global Health 5050 [30] has shown that more females are being vaccinated than males in many countries, including Brazil and U.S., as also shown by local media [31-33].

Considering the mental health impact due the pandemic, it was also observed that females experienced more depression symptoms after lockdown while males experienced more anxiety symptoms [34], but after a few weeks the genderdifferences disappeared and both groups experienced resilience feelings [35]. The mental impact of the pandemic in LMICs varied from immediate distress and discrimination experienced mainly by healthcare workers to long-term side effects such as higher prevalence of depression and other mood disorders as a result of social isolation, job insecurity, unemployment and economic distress [36].

It has been suggested that some individuals (named "superspreaders") are able to transmit the virus to a great number of persons [37]. However, it is not known if this could be explained by behavior (men speaking louder without mask) or biologically (differences in lung capacity between sexes and ages). Biologically, viral transmission capability could be influenced by less aerosol emission by females and children [37]. These sex-based differences may be also associated with variances in biological pathways such as immune responses against SARS-CoV-2, the expression of X-chromosome-encoded genes [20], or both.

These observations led us to question whether the virus could be transmitted more frequently by men than by women, independently of protection measures, age and socio-economic status. In order to circumvent such differences, we have analyzed the virus transmission in couples who kept neither conjugal distancing during the infection period nor the use of protective measures. Moreover, the mean age did not differ significantly between spouses and both partners had a comparable socio-economic status.

In a previous genetic study with 81 discordant couples for COVID-19, where one person was infected and symptomatic while the partner remained asymptomatic and serum-negative (despite remaining in close contact and sharing the same bed throughout the disease), we observed that there were significantly more women in the asymptomatic group [38]. Subsequently, there were reports of couples where the wife was infected by SARS-CoV-2 and clinically affected while the husband remained asymptomatic despite the close contact throughout the infection period. Some months later, the previously asymptomatic husbands beame infected and symptomatic after contact with male patients. 


\section{Methods}

We present an epidemiological survey (from July 2020 to July 2021) including 1744 adult Brazilian couples who were living together during the COVID-19 infection without protective measures. Their ages ranged from 20 to 70 years (overall mean age of 45 years, 44 for women and 46 for men). The positive diagnosis in symptomatic individuals was confirmed by RT-PCR and/or serology for the infected partners while negative results in both tests were confirmed in non-infected partners. These individuals presented complete information related to the infection event, sex, age, and diagnostic tests results. They were divided in two groups: (a) concordant couples where one spouse infected with confirmed COVID19 transmitted the infection to the partner and (b) discordant couples where one SARS-CoV-2 infected spouse was symptomatic while the partner was not, as confirmed by negative RT-PCR and serology results after viral exposure. The concordant and discordant couples were then subdivided according to which partner was infected first: men or women and women to men. Our whole data collection rationale from partners is presented in Fig. 1.

\section{Results}

As seen in Table 1, concordant couples analysis showed that men are significantly more infectious than women, with an estimated chance of $146 / 230=0.635$ (95\% confidence interval: $0.569-0.697)$ of being the first one affected. The corresponding female values were $84 / 230=0.365$ ( $95 \%$ confidence interval $0.303-0.431)$. These differences in male/female values are statistically significant $\left(\chi^{2}=16.713, \mathrm{P} \ll 0.0005\right)$.

The analysis of the group of discordant couples showed again that men are preferentially affected, with a probability estimated as $797 / 1367=0.583$ (95\% confidence interval: $0.557-0.609)$. The corresponding female values were $570 / 1367=0.417$ (95\% confidence interval: $0.391-0.443$ ). The combination of data from concordant and discordant couples showed that the man is preferentially affected in $146+797=943$ occurrences and the woman in $84+576=660$ instances $\left(\chi^{2}=49.962, P \ll 0.0005\right)$.

Interestingly, the analysis of COVD-19 reports of the present cohort showed that some $62 \%$ among those who mentioned keywords as "fear", "excessive care", "pandemic worries" and "anxiety" were sent by females. This observation is consistent with the results of a Brazilian survey with 4693 adults which showed that among $55 \%$ who declared that they were worried about the pandemic $62 \%$ were females and $45 \%$ males [39]. Such observation reporting that men were less worried about the pandemic than women could provide an explanation for their less protective behavior.

\section{Discussion}

All the results obtained in the present study strongly suggest that males are not only more susceptible to COVID-19 severity, as shown in worldwide epidemiological surveys, but they are also more likely to transmit the virus to their partners when compared to females in the household transmission context. The epidemiological findings in the present survey are consistent with the results of other published studies involving couples where one of the partners was infected by their spouses $[40,41]$. Female individuals aged between 17 and 65 years were also frequently found to be secondary cases [41].

Aiming to analyze a more homogeneous cohort and since age is an important predictor of severity and risk of death by COVID-19, we focused our survey on couples of comparable ages and economic status and therefore similar access to health care. It is also important to note that the survey was performed before the vaccination was started.

One of the possible current biological hypotheses for such gender variable transmission rate is a differential viral load in saliva, which has been explored as an important clinical measure of disease severity due to its positive association with many COVID-19 inflammatory markers [42]. These factors, together with the higher adoption of hygiene and protective measures among females, may justify the lower transmission rates in this group.

Interestingly, in a recent study of our group [43] it was observed that, although there were no observed gender differences in viral load in nasopharyngeal samples, adult males showed a significantly higher viral load in saliva samples (verified by RT-LAMP viral testing) than adult women. 
Fig. 1 Survey data collection rational diagram

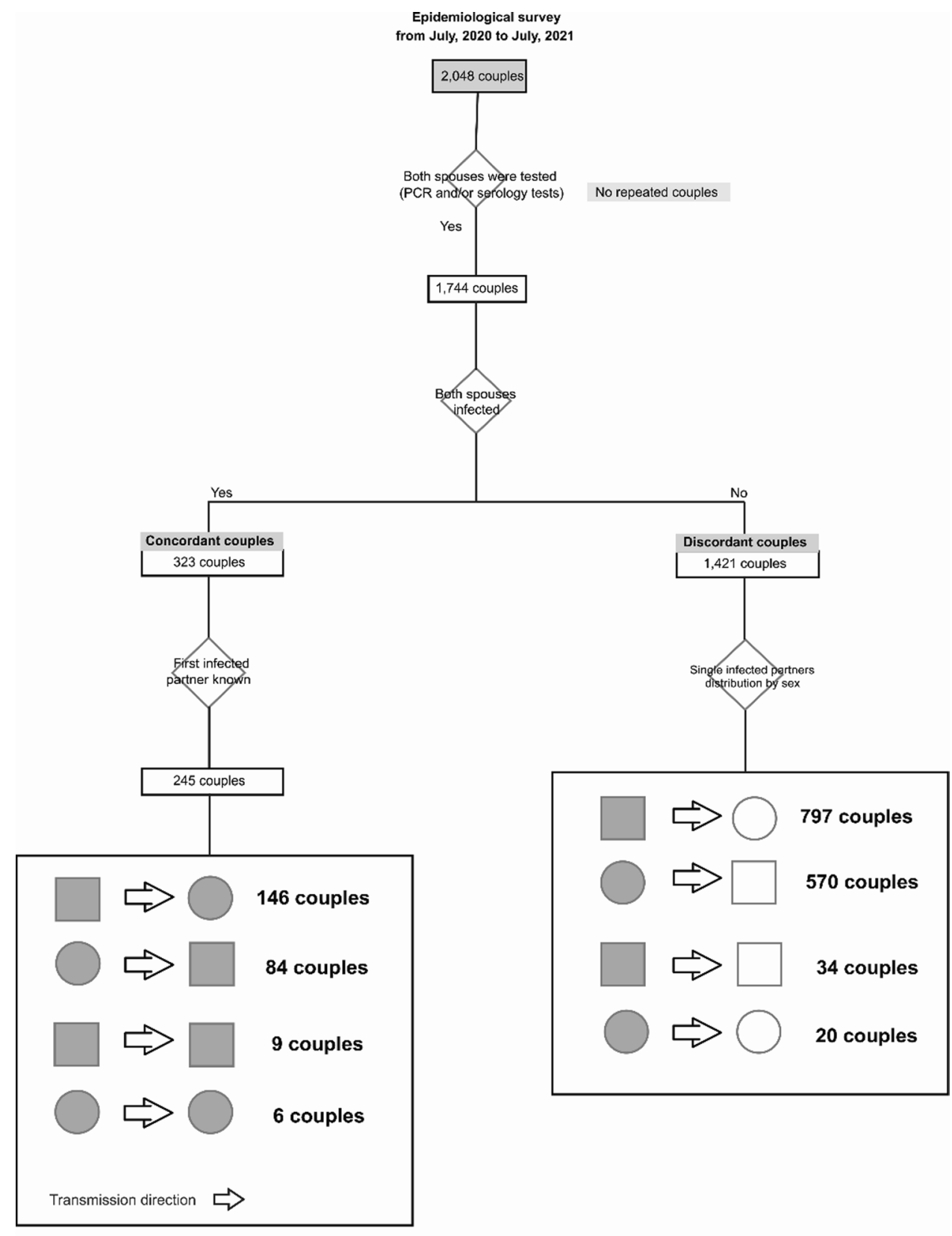

\section{LEGEND:}

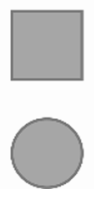

PCR and/or serum-positive male

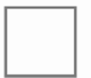

PCR and serum-negative male

PCR and/or serum-positive female

PCR and serum-negative female
Table 1 Numerical description of couple groups composition and chi-square $\left(\chi^{2}\right)$ values

\begin{tabular}{lcccc}
\hline Group & Men & Women & Total & $\begin{array}{l}\text { Chi-square } \\
\left(\chi^{2}\right) \text { values }\end{array}$ \\
\hline Discordant & 797 & 570 & 1367 & 37.6950 \\
Concordant & 146 & 84 & 230 & 16.7130 \\
\hline
\end{tabular}


These observations, together with the evidence of higher aerosol emission by men which makes them more likely to be "superspreaders" than women, support the hypothesis that male individuals are more efficient virus transmitters than females, which is related to biological and behavioral aspects.

This study has some limitations regarding the relatively modest number of couples included in the present cohort when compared with other epidemiological surveys of in-house transmission [40,41]. Additionally, the couples who responded the questionnaire are on average younger than the mean age of the population since, in Brazil, younger people have more access and familiarity with internet than older adults [44]. Nevertheless, our study brings new knowledge to the field of public health regarding SARS-CoV-2 transmission dynamics.

In short, the present study confirmed the existence of gender differences not only for susceptibility to infection and resistance to COVID-19 but also in the transmission rate.

Acknowledgements The authors are extremely grateful to all volunteers for their participation and collaboration. This work was supported by the Sao Paulo Research Foundation (FAPESP/Brazil) [Grant Numbers 2013/08028-1, 2014/50931-3 and 2020/09702-1], the National Council for Scientific and Technological Development (CNPq) [Grant Number 465355/2014-5], JBS S.A [Grant Number 69004]. Special thanks to Brazilian senator Mara Gabrilli for financial support.

Authors' contributions MVRS and MVC: methodology, formal analysis, investigation, data curation, writing一original draft, writing一review and editing and visualization. MRPB: conceptualization and writing - review and editing. PAO: methodology, formal analysis, investigation, data curation, writing —original draft and writing — review and editing. MSN: conceptualization and writing —review and editing. MZ: supervision, project administration, conceptualization, funding acquisition and writing-review and editing. All authors read and approved the final manuscript.

Data availability Data sharing is not applicable to this article as no datasets were generated during the current study.

\section{Declarations}

Ethics approval and consent to participate This study was approved by the Committee for Ethics in Research of the Institute of Biosciences at the University of São Paulo (CAAE 34786620.2.0000.5464) in accordance with de Declaration of Helsinki principles, ICH06 Good Clinical Practices and Brazilian Health Regulatory Agency (ANVISA) resolution number 466 from 2012 that regulates research with humans. An informed consent term was obtained from all participants.

Competing interests The authors declare no conflicts of interest.

Open Access This article is licensed under a Creative Commons Attribution 4.0 International License, which permits use, sharing, adaptation, distribution and reproduction in any medium or format, as long as you give appropriate credit to the original author(s) and the source, provide a link to the Creative Commons licence, and indicate if changes were made. The images or other third party material in this article are included in the article's Creative Commons licence, unless indicated otherwise in a credit line to the material. If material is not included in the article's Creative Commons licence and your intended use is not permitted by statutory regulation or exceeds the permitted use, you will need to obtain permission directly from the copyright holder. To view a copy of this licence, visit http://creativecommons.org/licenses/by/4.0/.

\section{References}

1. Chai S, Li Y, Li X, Tan J, Abdelrahim MEA, Xu X. Effect of age of COVID-19 inpatient on the severity of the disease: a meta-analysis. Int J Clin Pract. 2021;75(10): e14640.

2. Thakur B, Dubey P, Benitez J, Torres JP, Reddy S, Shokar N, et al. A systematic review and meta-analysis of geographic differences in comorbidities and associated severity and mortality among individuals with COVID-19. Sci Rep. 2021;11(1):8562.

3. Zhou F, Yu T, Du R, Fan G, Liu Y, Liu Z, et al. Clinical course and risk factors for mortality of adult inpatients with COVID-19 in Wuhan, China: a retrospective cohort study. Lancet. 2020;395(10229):1054-62.

4. Mallapaty $S$. The coronavirus is most deadly if you are older and male-new data reveal the risks. Nature. 2020;585(7823):16-7.

5. Peckham H, de Gruijter NM, Raine C, Radziszewska A, Ciurtin C, Wedderburn LR, et al. Male sex identified by global COVID-19 meta-analysis as a risk factor for death and ITU admission. Nat Commun. 2020;11(1):6317.

6. Dehingia N, Raj A. Sex differences in COVID-19 case fatality: do we know enough? Lancet Glob Health. 2021;9(1):e14-5.

7. Lam AA, Lepe A, Wild SH, Jackson C. Diabetes comorbidities in low- and middle-income countries: an umbrella review. J Glob Health. 2021;11:04040.

8. Geldsetzer P, Manne-Goehler J, Marcus M-E, Ebert C, Zhumadilov Z, Wesseh CS, et al. The state of hypertension care in 44 low-income and middle-income countries: a cross-sectional study of nationally representative individual-level data from 1.1 million adults. Lancet Lond Engl. 2019;394(10199):652-62.

9. Taylor L. Covid-19: Brazil's hospitals close to collapse as cases reach record high. BMJ. 2021;23(372): n800.

10. Aborode AT, Corriero AC, Fajemisin EA, Hasan MM, Kazmi SK, Olajiga O. Dengue and coronavirus disease (COVID-19) syndemic: double threat to an overburdened healthcare system in Africa. Int J Health Plan Manag. 2021. https://doi.org/10.1002/hpm.3334. 
11. Bong C-L, Brasher C, Chikumba E, McDougall R, Mellin-Olsen J, Enright A. The COVID-19 pandemic: effects on low- and middle-income countries. Anesth Analg. 2020;131(1):86-92.

12 Islam Z, Kokash DM, Babar MS, Uday U, Hasan MM, Rackimuthu S, et al. Food security, conflict, and COVID-19: perspective from Afghanistan. Am J Trop Med Hyg. 2021. https://doi.org/10.4269/ajtmh.21-1058.

13. Li SL, Pereira RHM, Prete CA Jr, Zarebski AE, Emanuel L, Alves PJH, et al. Higher risk of death from COVID-19 in low-income and non-White populations of São Paulo, Brazil. BMJ Glob Health. 2021;6(4): e004959.

14. Hasan MM, Rocha ICN, Ramos KG, Cedeño TDD, dos Santos Costa AC, Tsagkaris C, et al. Emergence of highly infectious SARS-CoV-2 variants in Bangladesh: the need for systematic genetic surveillance as a public health strategy. Trop Med Health. 2021;49(1):69.

15. Rocha R, Atun R, Massuda A, Rache B, Spinola P, Nunes L, et al. Effect of socioeconomic inequalities and vulnerabilities on health-system preparedness and response to COVID-19 in Brazil: a comprehensive analysis. Lancet Glob Health. 2021;9(6):e782-92.

16 Guedes MBOG, de Assis SJC, Sanchis GJB, Araujo DN, Oliveira AGRDC, Lopes JM. COVID-19 in Brazilian cities: impact of social determinants, coverage and quality of primary health care. PLoS ONE. 2021;16(9): e0257347.

17. Rackimuthu S, Hasan MM, Bardhan M, Essar MY. COVID-19 vaccination strategies and policies in India: the need for further re-evaluation is a pressing priority. Int J Health Plan Manag. 2021. https://doi.org/10.1002/hpm.3321.

18. Ghosh S, Moledina N, Hasan MM, Jain S, Ghosh A. Colossal challenges to healthcare workers combating the second wave of coronavirus disease 2019 (COVID-19) in India. Infect Control Hosp Epidemiol. 2021;2:1-2.

19. Vahidy FS, Pan AP, Ahnstedt H, Munshi Y, Choi HA, Tiruneh Y, et al. Sex differences in susceptibility, severity, and outcomes of coronavirus disease 2019: cross-sectional analysis from a diverse US metropolitan area. PLoS ONE. 2021;16(1): e0245556.

20. Klein SL, Flanagan KL. Sex differences in immune responses. Nat Rev Immunol. 2016;16(10):626-38.

21. Galasso V, Pons V, Profeta P, Becher M, Brouard S, Foucault M. Gender differences in COVID-19 attitudes and behavior: panel evidence from eight countries. Proc Natl Acad Sci. 2020;117(44):27285-91.

22. Howard MC. Gender, face mask perceptions, and face mask wearing: are men being dangerous during the COVID-19 pandemic? Personal Individ Differ. 2021;15(170): 110417.

23. Capraro V, Barcelo H. The effect of messaging and gender on intentions to wear a face covering to slow down COVID-19 transmission. PsyArXiv; 2020. https://psyarxiv.com/tg7vz/. Accessed 24 Oct 2021.

24. Suen LKP, So ZYY, Yeung SKW, Lo KYK, Lam SC. Epidemiological investigation on hand hygiene knowledge and behaviour: a cross-sectional study on gender disparity. BMC Public Health. 2019;11(19):401.

25. Kollamparambil U, Oyenubi A. Behavioural response to the Covid-19 pandemic in South Africa. PLoS ONE. 2021;16(4): e0250269.

26. Baack BN. COVID-19 vaccination coverage and intent among adults aged 18-39 years-United States, March-May 2021. MMWR Morb Mortal Wkly Rep. 2021;70. https://www.cdc.gov/mmwr/volumes/70/wr/mm7025e2.htm. Accessed 24 Oct 2021.

27. Hesse, M. Women might be more skeptical of the covid vaccine. Why? The Washington Post. https://www.washingtonpost.com/lifestyle/ style/women-covid-vaccine-skeptical/2020/12/15/63551cac-3a61-11eb-9276-ae0ca72729be_story.html. Accessed 24 Oct 2021.

28. Loomba S, de Figueiredo A, Piatek SJ, de Graaf K, Larson HJ. Measuring the impact of COVID-19 vaccine misinformation on vaccination intent in the UK and USA. Nat Hum Behav. 2021;5(3):337-48.

29. Solís Arce JS, Warren SS, Meriggi NF, Scacco A, McMurry N, Voors M, et al. COVID-19 vaccine acceptance and hesitancy in low- and middleincome countries. Nat Med. 2021;27(8):1385-94.

30. Global Health 50/50. The COVID-19 sex-disaggregated data tracker | global health 50/50. https://globalhealth5050.org/the-sex-genderand-covid-19-project/the-data-tracker/. Accessed 24 Oct 2021.

31. Nedelman M. January 14, 2021 coronavirus news. https://edition.cnn.com/world/live-news/coronavirus-pandemic-vaccine-updates-0114-21/h_4e7c384a6d1b631c1ed48cef287256be. Accessed 24 Oct 2021.

32. Viana T. Mulheres se vacinam mais contra a Covid-19 do que homens no Ceará; $56 \%$ dos óbitos são masculinos - Metro - Diário do Nordeste. https://diariodonordeste.verdesmares.com.br/metro/mulheres-se-vacinam-mais-contra-a-covid-19-do-que-homens-no-ceara-56-dosobitos-sao-masculinos-1.3100266. Accessed 24 Oct 2021.

33. Ungar L. The gender vaccine gap: more women than men are getting Covid shots | Kaiser health news. https://khn.org/news/article/ gender-vaccine-gap-more-women-than-men-vaccinated-against-covid/. Accessed 24 Oct 2021

34. Vloo A, Alessie RJM, Mierau JO, Boezen MH, Mierau JO, Franke L, et al. Gender differences in the mental health impact of the COVID-19 lockdown: longitudinal evidence from the Netherlands. SSM Popul Health. 2021;15: 100878.

35. Fenollar-Cortés J, Jiménez Ó, Ruiz-García A, Resurrección DM. Gender differences in psychological impact of the confinement during the COVID-19 outbreak in Spain: a longitudinal study. Front Psychol. 2021;12:2279.

36. Kola L, Kohrt BA, Hanlon C, Naslund JA, Sikander S, Balaji M, et al. COVID-19 mental health impact and responses in low-income and middle-income countries: reimagining global mental health. Lancet Psychiatry. 2021;8(6):535-50.

37. Lewis D. Superspreading drives the COVID pandemic — and could help to tame it. Nature. 2021;590(7847):544-6.

38. Castelli EC, de Castro MV, Naslavsky MS, Scliar MO, Silva NSB, Andrade HS, et al. MHC variants associated with symptomatic versus asymptomatic SARS-CoV-2 infection in highly exposed individuals. Front Immunol. 2021;12:3898.

39. Sponchiato D. Pesquisa mostra o grau de medo e tensão dos brasileiros com o coronavírus | Veja Saúde. https://saude.abril.com.br/ mente-saudavel/medo-e-tensao-brasileiros-coronavirus/. Accessed 24 Oct 2021.

40. Bi Q, Lessler J, Eckerle I, Lauer SA, Kaiser L, Vuilleumier N, et al. Insights into household transmission of SARS-CoV-2 from a populationbased serological survey. Nat Commun. 2021;12(1):3643.

41. Hall J, Harris R, Zaidi A, Woodhall S, Dabrera G, Dunbar J. HOSTED—England's household transmission evaluation dataset: preliminary findings from a novel passive surveillance system of COVID-19. Int J Epidemiol. 2021;50(3):743-52.

42. Silva J, Lucas C, Sundaram M, Israelow B, Wong P, Klein J, et al. Saliva viral load is a dynamic unifying correlate of COVID-19 severity and mortality. MedRxiv Prepr Serv Health Sci. 2021. https://doi.org/10.1101/2021.01.04.21249236.

43. Kobayashi GS, Brito LA, Moreira DDP, Suzuki AM, Hsia GSP, Pimentel LF, et al. A novel saliva RT-LAMP workflow for rapid identification of COVID-19 cases and restraining viral spread. Diagnostics. 2021;11(8):1400.

44. Brazil: share of internet users by age group 2020 | Statista. https://www.statista.com/statistics/254724/age-distribution-of-internet-usersin-brazil/. Accessed 27 Dec 2021. 
Publisher's Note Springer Nature remains neutral with regard to jurisdictional claims in published maps and institutional affiliations. 